\title{
"Family Medicine Approach sebagai Tatalaksana Benign Paroxysmal Positional Vertigo (BPPV) Kanal Posterior Kanan Komorbid Hipertensi pada Perempuan Usia 49 Tahun: Sebuah Laporan Kasus"
}

\author{
Angga Hendro Priyono ${ }^{1}$, Azelia Nusadewiarti ${ }^{2}$ \\ ${ }^{1}$ Program Profesi Dokter Universitas Lampung / Dokter Muda RSUD Dr. Hi. Abdul Moeloek, Lampung \\ ${ }^{2}$ Departemen Kedokteran Komunitas-Okupasi, Fakultas Kedokteran Universitas Lampung, Lampung
}

\begin{abstract}
ABSTRAK
Insidensi terjadinya kasus BPPV di dunia mencapai 64/100.000 yang paling banyak melibatkan kanalis semisirkularis posterior unilateral. Lima puluh persen penyebabnya adalah idiopatik, diikuti dengan kasus trauma kepala, neuritis vestibularis, migrain, implantasi gigi dan mastoiditis kronis. Sebuah kasus pusing berputar disertai dengan mual dan muntah pada perempuan usia 49 tahun sejak 3 jam sebelum datang ke Puskesmas Rawat Inap Simpur. Pasien memiliki riwayat vertigo sejak 3 tahun lalu dan riwayat hipertensi sejak 1,5 tahun yang lalu. Pemeriksaan fisik didapatkan tekanan darah 150/90 mmHg dengan IMT 25,3 (pemeriksaan fisik lain dalam batas normal). Pemeriksaan neurologis otologi didaptkan hasil Dix-Hallpike maneuver vertigo positif dengan nistagmus cepat ke kiri. Dilakukan intervensi dengan pendekatan dokter keluarga berupa tindakan Epley manuver selama perawatan di puskesmas serta pemberian betahistin mesylate 3 × $6 \mathrm{mg}$, difenhidramin $\mathrm{HCl} 4 \times 25 \mathrm{mg}$, dan kaptopril 1 x $12,5 \mathrm{mg}$. Saat pulang pasien diberikan edukasi mengenai latihan vestibuler berupa Brandt-Daroff maneuver dan pola hidup sehat. Dilakukan follow up pada pasien sebanyak 4 kali dan didapatkan hasil keluhan berkurang lebih dari 50\% sejak datang ke puskesmas, pusing hanya terasa pada saat bangun dari tidur. Penatalaksanaan BPPV kanalis posterior kanan yang diberikan pada kasus ini sudah sesuai dengan guideline dan penelitian terkini, terlihat perkembangan yang baik pada gejala klinis dan perubahan perilaku pasien setelah dilakukan intervensi berdasarkan evidence based medicine yang bersifat patient centred dan family approach.
\end{abstract}

Kata Kunci: BPPV, Dokter Keluarga, Kanal Posterior Kanan, Unilateral

\section{ABSTRACT}

The incidence of Benign Paroxysmal Positional Vertigo (BPPV) has been reported 64/100.000 in the world which mostly involves the unilateral posterior semicircular canal. Fifty percent of the cases are idiopathic, followed by cases of head trauma, vestibular neuritis, migraine, dental implantation, and chronic mastoiditis. Case: A Dizziness, nausea, and vomiting in 49 years old woman who came to the Simpur Primary Health Care (PHC) have been reported. She appeared to be overweight with BMI is 25,3. Her physical examinations were normal except blood pressure is 150/90 $\mathrm{mmHg}$ and DixHallpike vertigo positive maneuver with fast nystagmus to the left. Family medicine approach was carried out as holistic and comprehensive management by performing Epley maneuvers during treatment at the PHC and the administration $3 \times 6 \mathrm{mg}$ of betahistine mesylate, $4 \times 25 \mathrm{mg}$ of diphenhydramine $\mathrm{HCl}$, and $1 \times 12.5 \mathrm{mg}$ of captopril. Brandt-Daroff maneuver and healthy lifestyle education were given to her before she came home. There were 4 times follow-ups for patient and the results of complaints were reduced by more than 50\% since coming to the PHC, dizziness was only felt when she is waking up from sleep. The diagnosis and management were given to the patient are by the guidelines and current research, there is a good development in clinical symptoms and changes in patient behavior after patient-centered and family approach intervention based on "evidence-based medicine".

Keywords: BPPV, Family Psychian, Right Posterior Channel, Unilateral 


\section{PENDAHULUAN}

Sistem vestibuler merupakan suatu sistem keseimbangan yang berperan terhadap persepsi gerakan, posisi kepala serta orientasi ruang secara relatif terhadap gravitasi. Informasi yang diterima organ vestibuler dan jaras sarafnya, memungkinkan untuk menjaga stabilitas postural melalui refleks vestibulookuler dan vestibulospinal. ${ }^{[1]}$ Bila terjadi gangguan pada sistem vestibuler, maka akan menyebabkan vertigo. Vertigo merupakan persepsi yang salah dari gerakan seseorang atau lingkungan sekitarnya. Persepsi tersebut dapat berupa rasa melayang, mengambang yang timbul akibat gangguan sistem proprioseptif atau sistem visual, dikenal sebagai vertigo vestibuler, dan persepsi berupa rasa berputar yang timbul akibat gangguan pada sistem vestibuler, dikenal sebagai vertigo vestibuler. Berdasarkan letak lesinya, vertigo vestibuler dibagi menjadi dua, yaitu vertigo vestibuler perifer dengan lesi pada labirin dan nervus vestibularis, dan vertigo vestibuler sentral dengan lesi pada nukleus batang otak, thalamus hingga ke korteks serebri. ${ }^{[2]}$ Benign Paroxysmal Positional Vertigo (BPPV) merupakan suatu gangguan klinis berupa gangguan vestibuler perifer yang bersifat subjektif dan paling banyak terjadi di dunia. Gejala rasa pusing berputar secara tiba - tiba diikuti mual muntah dan keringat dingin, yang dipicu oleh perubahan posisi kepala terhadap gaya gravitasi tanpa adanya keterlibatan lesi di susunan saraf baik pusat maupun perifer. ${ }^{[3]}$ Insidensi yang terjadi dari BPPV ini adalah 64/100.000 yang pada umumnya melibatkan kanalis semisirkularis posterior dengan angka resolusi lebih dari $85 \%$ setelah terapi reposisi kanalith. ${ }^{[4]}$ Pasien dengan keluhan dan gejala yang sesuai dengan BPPV, harus disesuaikan dengan kriteria diagnostik BPPV kanalis posterior itu sendiri. Sekitar 50\%, penyebab BPPV adalah idiopatik, selain idiopatik, penyebab terbanyak adalah trauma kepala diikuti dengan neuritis vestibularis, migrain, implantasi gigi dan operasi telinga, ataupun mastoiditis kronis. ${ }^{[4,5]}$

Mayoritas pasien dengan BPPV datang ke fasilitas layanan primer atau Unit Gawat Darurat (UGD) sebelum datang ke spesialis saraf dengan keluhan pusing kepala berputar. Penting bagi tenaga medis di fasilitas layanan primer untuk mengetahui kanal yang terkena. Hal itu dapat bermanfaat dalam melakukan terapi untuk mencegah rekurensi. ${ }^{[6,7]}$

Cara untuk menegakkan diagnosis BPPV harus dilakukan dalam beberapa tahap. Anamnesis sebagai tahap pertama, harus ditanyakan faktor - faktor yang merupakan etiologi atau penyakit penyerta yang dapat mempengaruhi keberhasilan terapi, seperti riwayat diabetes, hipertensi, trauma kepala, stroke, migrain dan riwayat gangguan keseimbangan atau riwayat gangguan saraf sebelumnya. ${ }^{[5,6]}$ Berdasarkan hasil penelitian, hipertensi berhubungan dengan peningkatan terjadinya BPPV berulang. ${ }^{[8]}$ Tahap selanjutnya, anamnesis dikonfirmasi dengan pemeriksaan fisik berupa DixHallpike maneuver untuk memastikan adanya keterlibatan kanalis semisirkularis dengan terlebih dahulu diinformasikan kepada pasien bahwa tindakan yang dilakukan bertujuan untuk memprovokasi serangan vertigo. ${ }^{[4]}$

Keluhan yang selalu datang secara tiba-tiba membuat pasien dengan BPPV merasa tidak nyaman. Hal ini terjadi karena penatalaksanaan secara holistik dan komprehensif terhadap penyakit seorang pasien jarang dilakukan, sehingga diperlukan suatu tatalaksana komprehensif guna mengurangi angka morbiditas.

\section{ILUSTRASI KASUS}

\section{Anamnesis}

Pasien perempuan, Ny. SS, umur 49 tahun, bekerja sebagai ibu rumah tangga, datang bersama suaminya ke Puskesmas Rawat Inap Simpur pada tanggal $06 \mathrm{Mei}$ 2019 dengan keluhan rasa pusing berputar 
secara subjektif dirasakan sejak 3 jam Sebelum Masuk Rumah Sakit (SMRS). Rasa pusing berputar dirasakan pasien sewaktu baru bangun dari tidur, pada saat melakukan gerakan rukuk dan bersujud sewaktu shalat subuh. Pasien merasakan lingkungan disekelilingnya berputar.Rasa berputar berlangsung sekitar 1-2 menit dan hilang dengan sendirinya. Keluhan lain berupa mual dan muntah disertai keringat dingin dialami pasien. Pasien belum mengonsumsi obat-obatan sampai datang ke puskesmas.

Pasien pernah mengalami keluhan serupa sebelumnya sejak tiga tahun yang lalu. Intensitas serangan makin lama makin berkurang, hilang timbul, muncul jika pasien merubah posisi kepala, terutama jika pasien tidur miring kekanan.Terdapat riwayat mendengung pada telinga sebelah kanan. Pasien juga memiliki riwayat hipertensi sejak 1,5 tahun yang lalu. Selama menderita hipertensi, pasien mengonsumsi obat amlodipin $5 \mathrm{mg}$ sebanyak satu kali sehari. Pasien rutin mengonsumsi makanan berlemak dan yang mengandung santan serta pasien menjalani olahraga secara tidak rutin. Pasien mengaku makan teratur setiap hari.

\section{Pemeriksaan Fisik}

Pada pemeriksaan fisik didapatkan keadaan umum tampak sakit sedang, komposmentis E4 V5 M6 dan kooperatif. Tekanan darah 150/90 $\mathrm{mmHg}$, nadi 86x/menit, frekuensi pernapasan $16 \mathrm{x} /$ menit, suhu $36,9^{\circ} \mathrm{C}$. berat badan 57 $\mathrm{kg}$, tinggi badan $150 \mathrm{~cm}$, Status gizi 25,3 overweight (berdasarkan IMT).

\section{Status Generalis}

Rambut, mata, telinga, hidung dan tenggorokan kesan dalam batas normal. Paru, gerak dada dan fremitus taktil simetris, tidak terdengar adanya ronkhi dan wheezing di kedua lapang paru, kesan dalam batas normal. Batas jantung tidak melebar, kesan pemeriksaan jantung dalam batas normal. Pemeriksaan abdomen inspeksi cembung dan simetris, auskultasi didapatakan bising usus normal, perkusi timpani pada 9 regio abdomen, palpasi tidak didapatkan nyeri tekan. Ekstremitas, tidak ditemukan edema, kesan dalam batas normal. Muskuloskeletal dan status neurologis dalam batas normal.

\section{Status Neurologis Otologi}

Tes penala memberi kesan normal. Pemeriksaan keseimbangan sederhana (tes Romberg, tes Tandem Romberg, Fukuda stepping test, nose to finger test, dan past pointing test) memberikan kesan normal. Pemeriksaan dilanjutkan dengan melakukan Dix-Hallpike maneuver, dimulai dengan kepala ditolehkan ke kiri, tidak ditemukan adanya vertigo dan nistagmus. Pada saat dilakukan DixHallpike maneuver ke kanan, setelah lebih kurang sepuluh detik, pasien mengeluhkan rasa pusing berputar yang hebat dan terlihat adanya nistagmus posisional dengan fase cepat ke arah kiri. Pasien tidak dapat menahan muntah yang disertai keringat dingin sehingga Dix-Hallpike maneuver tidak dilanjutkan.

\section{Pemeriksaan Penunjang}

Hasil pemeriksaan laboratorium rutin: Hemogoblin 12,5g/dl (11,7 - 15,5g/dl),

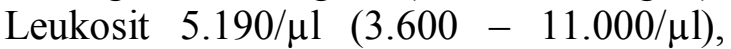
Eritrosit $4,3 \times 10^{6} / \mu 1\left(3,8-5,2 \times 10^{6} / \mu 1\right)$, Hematokrit 37\% $(35-47 \%)$, Trombosit

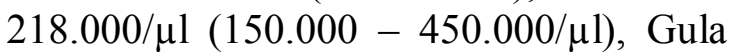
Darah Sewaktu $121 \mathrm{mg} / \mathrm{dl}(<140 \mathrm{mg} / \mathrm{dl})$, $\mathrm{Na}^{+} 140 \mathrm{mmol} / \mathrm{l}(135-147 \mathrm{mmol} / \mathrm{l})$, $\mathrm{Ca}^{2+} 9 \mathrm{mg} / \mathrm{dl}(8,5-10 \mathrm{mg} / \mathrm{dl}), \mathrm{Cl}^{-} 100$ $\mathrm{mmol} / \mathrm{l}(95$ - $105 \mathrm{mmol} / \mathrm{l}), \mathrm{K}^{+} 4 \mathrm{mmol} / \mathrm{l}$ (3,5 - $5 \mathrm{mmol} / \mathrm{l})$. Tampak kesan normal.

\section{Data Keluarga}

Pasien merupakan anak kedua dari tiga bersaudara, orangtua pasien tinggal di daerah Kotabumi, Lampung Utara. Saat ini pasien tinggal bersama suaminya, yaitu Tn. AY yang berusia 54 tahun dan dua orang anaknya yaitu Sdr. DD yang berusia 26 tahun dan Nn. P yang berusia 20 tahun. Menurut siklus Duvall, siklus keluarga ini berada pada tahap VI yaitu tahapkeluarga 
melepas anak usia dewasa muda (anak yang meninggalkan rumah). Pasien beraktivitas sehari - hari sebagai ibu rumah tangga. Seluruh permasalahan keluarga dimusyawarahkan bersama dan diputuskan oleh suaminya sebagai kepala keluarga. Kebutuhan materi keluarga dipenuhi dari penghasilan kepala keluarga sebagai buruh di pasar tradisional yaitu sekitar Rp.50.000,-/hari, anak laki lakinya yang bekerja sebagai karyawan tidak tetap di toko elektronik dengan penghasilan Rp.1.500.000,-/bulan dan anak perempuannya sebagai tukang gigi dengan penghasilan rata - rata Rp.1.000.000,-/bulan. Seluruh anggota keluarga memiliki asuransi kesehatan.

Hubungan pasien dengan suami dan anak-anaknya cukup erat karena bertemu setiap hari dan berinteraksi baik satu sama lain. Pasien menampung semua keluh kesah baik dari suami dan anak-anak pasien. Hubungan anak - anak pasien dengan suami pasien baik, tetapi tidak terlalu dekat. Hal ini dikarenakan suami pasien selalu pulang larut malam setiap hari setelah pulang bekerja. Setiap anggota keluarga mendukung anggota keluarga lain yang sakit. Perilaku berobat keluarga yaitu memeriksakan keluarganya yang sakit ke layanan kesehatan. Keluarga pasien berobat ke Puskesmas Rawat Inap Simpur yang berjarak \pm 2 kilometer dari rumah pasien.

\section{Family APGAR Score}

Dinamika keluarga Ny.SS dapat dilihat dari berdasarkan Family APGAR Score sebagai berikut:

$\begin{array}{ll}\text { Adaptation } & : 2 \\ \text { Partnership } & : 2 \\ \text { Growth } & : 1 \\ \text { Affection } & : 1 \\ \text { Resolve } & : 1\end{array}$

Total Family APGAR Score: 7 (fungsi keluarga moderat)

\section{Diagnosis Banding}

1. Benign Paroxysmal Positional Vertigo

2. Neuritis Vestibularis
3. Meniere Disease

4. Hipertensi

\section{Diagnosis Kerja}

Benign Paroxysmal Positional Vertigo

Kanal Posterior Kanan komorbid Hipertensi Derajat 1

Tata laksana Medikamentosa:

○ Betahistin mesylate $3 \times 6 \mathrm{mg}$

- Difenhidramin $\mathrm{HCl} 4 \times 25 \mathrm{mg}$

○ Captopril 1 x 12,5 mg

\section{Non-medikamentosa:}

- Edukasi kepada pasien dan keluarga mengenai penyakit Benign Paroxysmal Positional Vertigo (BPPV).

- Edukasi kepada pasien untuk segera datang kembali ke puskesmas jika keluhan datang tiba-tiba terutama menyebabkan hendaya dalam melakukan aktivitas sehari - hari.

- Edukasi kepada pasien dan keluarga mengenai kontrol tekanan darah secara rutin agar dapat mencegah kekambuhan BPPV dan menghindari komplikasi.

- Edukasi kepada pasien untuk makan makanan yang bergizi dan seimbang sesuai dengan anjuran dokter.

- Edukasi kepada pasien efek samping obat yang timbul, berapa lama pemakaian obat serta memberikan edukasi mengenai cara mengkonsumsi obat dengan tepat.

- Edukasi kepada pasien dan keluarga mengenai faktor - faktor yang dapat membuat keluhan berulang.

- Memberikan edukasi kepada keluarga untuk berperan dalam mengingatkan pasien mengenai latihan dengan metode Brandt-Daroff maneuver untuk mencegah kekambuhan serta gaya hidup yang sehat.

- Edukasi dan motivasi mengenai perlunya perhatian dukungan dari semua anggota keluarga terhadappenyakit pasien. Keluarga harus memberikan dorongan kepada pasien untuk mencari tahu penyebab dari penyakit yang diderita dan 
melakukan pencegahan terjadinya komplikasi.

\section{Prognosis :}

○ Quo ad vitam : ad bonam

○ Quo ad functionam : dubia ad bonam

○ Quo ad sanantionam : dubia ad bonam

\section{Follow up}

Pasien pulang setelah dilakukan perawatan di puskesmas Rawat Inap Simpur selama 3 hari dengan kondisi baik. Telah dilakukan kunjungan ke rumah sebanyak 4 kali untuk mengidentifikasi faktor risiko dalam keluarga, keberhasilan tata laksana dan edukasi lanjutan. Didapatkan perkembangan yang baik pada gejala klinis dan perubahan perilaku pasien setelah dilakukan tata laksana berdasarkan evidence based medicine yang bersifat patient centred dan family approach.

\section{PEMBAHASAN}

Benign Paroxysmal Positional Vertigo (BPPV) merupakan gangguan klinis dengan karakteristik berupa serangan vertigo perifer, berulang, singkat, dan berkaitan dengan perubahan posisi kepala baik dari tidur kemudian memutar kepala. ${ }^{[3]}$ Etiologi pada pasien ini adalah idiopatik, yang merupakan etiologi terbanyak untuk kasus BPPV..$^{[1,3]}$

Aparatus vestibularis adalah komponen khusus pada telinga yang dapat memberikan informasi mengenai sensasi keseimbangan serta koordinasi gerakangerakan kepala, mata dan posisi tubuh. Bagian vestibuler dari membran labirin ini terdiri atas 3 kanalis semisirkularis yaitu, anterior, horizontal, dan posterior. Labirin ini juga terdiri atas dua struktur otolit yaitu sakulus dan utrikulus yang mampu mendeteksi akselerasi linear termasuk pengaruh gravitasi bumi. Makula pada utrikulus diduga menjadi sumber partikel partikel kalsium yang dapat menyebabkan
BPPV berupa kalsium karbonat (otokonia) yang berbentuk matriks gelatinosa. Kristal kalsium karbonat ini memiliki densitas dua kali lipat dari endolimfe sehingga berespon terhadap perubahan gravitasi dan gerakan akselerasi yang lain.

Adanya debris otokonia yang terlepas dari makula utrikulus yang berdegenerasi, melekat di permukaan kupula (sensor gerakan) kanalis semisirkularis posterior yang letaknya paling bawah. ${ }^{[3]}$ Sistem vestibular akan terdegradasi dengan usia dan sebagai hasil dari perubahan yang disebabkan oleh hipertensi. Hipertensi akan memicu kerusakan pembuluh darah difus yang mengakibatkan penyakit aterosklerosis. Kerusakan pembuluh darah pada telinga bagian dalam yang disebabkan oleh aterosklerosis dapat mengakibatkan pelepasan otokonia secara progresif dari membran otolitik. ${ }^{[6]}$

Pergeseran massa otokonia membutuhkan waktu, menyebabkan adanya masa laten sebelum timbulnya keluhan vertigo dan nistagmus. Kristal otokonia yang bergerak di dalam kanalis semisirkularis akan menyebabkan endolimfe bergerak dan menstimulasi ampula dalam kanal sehingga menyebabkan vertigo. Nistagmus dibangkitkan oleh saraf ampularis yang tereksitasi di dalam kanal yang berhubungan langsung dengan muskulus ekstra okuler. ${ }^{[3]}$

Berdasarkan literatur diatas, terdapat hubungan yang cukup erat kaitannya antara gejala yang dirasakan pasien dengan hipertensi. Diagnosis BPPV kanalis posterior kanan komorbid hipertensi ditegakkan berdasarkan anamnesis adanya keluhan rasa pusing berputar sewaktu posisi kepala berubah, diikuti dengan gejala mual muntah dan keringat dingin yang pernah dialami sejak tiga tahun lalu dan riwayat hipertensi sejak satu setengah tahun lalu. Tes provokasi dengan DixHallpike maneuver menimbulkan vertigo hebat sewaktu kepala dimiringkan ke kanan dengan nistagmus posisional yang muncul sesudah 10 detik. Nistagmus 
posisional kanan muncul pada saat tes provokasi karena otokonia yang berada pada bagian posterior kanal bergerak dari atas kebawah secara torsional, sehingga mengakibatkan nistagmus posisional dengan fase cepat ke kiri. Nistagmus pada tipe kupulolithiasis tidak mempunyai fase laten, intensitas menetap selama kepala berada pada posisi provokatif dan tidak mempunyai fatigabilitas. Sebaliknya nistagmus pada tipe kanalolithiasis akan memperlihatkan adanya fase laten sebelum onset vertigo dengan onset yang lebih singkat sekitar satu menit dan mempunyai fatigabilitas. Kedua hal diatas sangat penting untuk dibedakan karena merupakan dasar penentuan letak lesi dan awal manuver terapi. ${ }^{[3,7]}$ Posisi telinga yang sakit ditentukan dengan membandingkan intensitas vertigo dan nistagmus serta arah dari fase cepat nistagmus. Pada pasien terdapat perbedaan intensitas yang bermakna yaitu pergerakan dari arah kanan dapat menimbulkan vertigo dan nistagmus.

Dix-Hallpike maneuver bernilai positif bila dijumpai adanya masa laten selama 5 - 20 detik setelah posisi kepala berubah hingga onset munculnya nistagmus dan vertigo, terjadi nystagmus dan vertigo secara bersamaan dengan intensitas yang meningkat dan membaik dalam 60 detik serta vertigo yang semakin berkurang setiap maneuver tersebut dilakukan berulang. ${ }^{[10]}$ Dix-Hallpike maneuveryang dilakukan pada pasien ini menimbulkan gejala vertigo, sehingga bisa disimpulkan bahwa terdapat otokonia pada kanalis posterior dan anterior. ${ }^{[2,11]}$ Bila pasien merubah posisi seperti Dix-Hallpike maneuver, posisi kanalis posterior berubah dari inforior ke superior sehingga kupula bergerak secara sentrifugal dan menimbulkan keluhan vertigo serta nistagmus. ${ }^{[5]}$ Secara statistik, BPPV yang paling banyak ditemui adalah BPPV kanalis posterior. Hal ini dapat terjadi karena BPPV kanalis horizontal dapat beremisi spontan pada saat kepala sejajar dengan bidang horizontal bumi. ${ }^{[2]}$ Saat dilakukan anamnesis dan pemeriksaan fisik, pasien memiliki penyakit hipertensi. Penyakit hipertensi dapat meningkatkan kejadian rekurensi pada penyakit BPPV. ${ }^{[8]}$ Menurut guideline, pasien dengan gejala khas BPPV dan hasil Dix-Hallpike maneuver yang positif pada saat tes provokasi, menandakan terdapat gangguan vertigo vestibuler kanal posterior karena Dix-Hallpike maneuver merupakan manuver provokasi yang terbaik untuk BPPV kanalis posterior. ${ }^{[5,11]}$

BPPV kanalis posterior dapat ditatalaksana dengan terapi medikamenotasa dan nonmedikamentosa berupa berbagai macam manuver terapi, namun yang terbanyak dan paling umum dipakai klinisi untuk tatalaksana BPPV kanalis posterior adalah Epley maneuver dengan efektifitas $>85 \%{ }^{[8]}$ Epley maneuver dapat dilakukan untuk BPPV kanalis posterior tipe kanalolitiasis. Pada pasien ini, nistagmus yang muncul merupakan nistagmus posisional mempunyai karakteristik yang sesuai dengan tipe kanalolithiasis, sehingga putaran Epley maneuver tetap dimulai dari telinga yang memperlihatkan vertigo dan nistagmus dengan intensitas yang kuat pada saat berada diposisi bawah. ${ }^{[3,7]}$

Pada saat pertama kali dilakukan manuver terapi, pasien tidak mampu menyelesaikan satu putaran, karena rasa pusing berputar dan gejala otonom yang muncul begitu hebat, sehingga diputuskan untuk tidak melanjutkan terapi dan diberikan pengobatan analog histamin yaitu betahistin mesylate yang dapat mengurangi tekanan endolimfatik dengan cara memperbaiki mikrosirkulasi serta pemberian vestibulosupresan yaitu difenhidramin $\mathrm{HCl}$ untuk mencegah kekambuhan. ${ }^{[9-11]}$ Selain itu diberikan nasehat agar tidur miring dengan telinga yang sakit berada di posisi atas. ${ }^{[3,7]}$ Untuk mengatasi hipertensi, pasien diberikan medikamentosa berupa kaptopril. Kaptopril merupakan obat golongan $A C E$ Inhibitor. ACE-Inhibitor salah satu lini pertama dalam tatalaksana hipertensi 
selain Amlodipin dari golongan Calcium Channel Blocker. ${ }^{[12,13]}$ Pemilihan obat $A C E$-Inhibitor pada pasien ini karena salah satu efek samping dari obat golongan Calcium Channel Blocker dapat menimbulkan vertigo. ${ }^{[14]}$ Epley maneuver dilanjutkan keesokan harinya dan pasien dapat melakukan secara lengkap Pasien dipulangkan setelah keadaan membaik dan tetap diberikan terapi medikamentosa.

Penatalaksanaan pada pasien dilakukan secara holistik dan komprehensif dengan melakukan kunjungan sebagai tindak lanjut dari tatalaksana pasien saat di puskesmas.

Setelah kunjungan awal (11 Mei 2019), berdasarkan konsep Mandala of Health, didapatkan bahwa dari segi perilaku kesehatan pasien mengutamakan kuratif dibandingkan tindakan preventif karena rendahnya pengetahun mengenai langkah pencegahan penyakit serta kurangnya penerapan pola hidup sehat. Pasien dan anggota keluarganya merupakan peserta KIS dan hanya datang ke puskesmas terdekat bila terdapat keluhan yang mengganggu aktivitasnya.

Menurut human biology, pasien merasakan pusing berputar disertai dengan mual dan muntah sejak 3 jam sebelum datang ke Puskesmas Rawat Inap Simpur. Pasien mengkonsumsi makanan berlemak dan bersantan serta pasien juga memiliki riwayat hipertensi. Mengenai hal ini pasien diberi edukasi untuk merubah variasi makanan dengan makanan yang bergizi dan seimbang. Pada pasien juga dijelaskan bahwa kekambuhan dari penyakit yang diderita saat ini disebabkan karena penyakit hipertensi yang di derita oleh pasien. Disarankan pasien mengkonsumsi obat hipertensi untuk mengontrol tekanan darah sehingga risiko kekambuhan menjadi berkurang.

Lingkungan psikososial, hubungan antar pasien dengan anak - anak pasien dinilai baik, tetapi yang membuat pasien sedikit cemas hubungan antar suami pasien dan anak - anak yang kurang dekat dikarenakan suami selalu pulang larut malam dan kurang berinteraksi dengan anak - anak. Dilakukan family conference untuk menengahi masalah ini. Suami pasien berniat merubah kebiasaannya serta semua anggota keluarga ingin mendukung pasien dalam mencari pengobatan ke pelayanan kesehatan terdekat dan membantu pasien untuk mengidentifikasi faktor penyebab kekambuhan sehingga dapat dihindari dan kesembuhan pasien dapat tercapai.Gaya hidup pasien yang mengkonsumsi makanan berlemak dan bersantan. Setelah digali faktor gaya hidup, diperoleh data bahwa pasien sudah memiliki kebiasaan mengkonsumsi gorengan dan makanan bersantan selama 3 tahun, hal tersebut membuat pasien merasa khawatir berhubungan dengan keluhannya saat ini.Pasien merasa kurang pengetahuan mengenai dampakmengkonsumsi makanan berlemak dan bersantan tanpa disertai gizi yang seimbang.Hal ini diperberat dengan kondisi penyakit pasien yang dapat menghambat pasien dalam melakukan aktivitas, sehingga kesulitan dalam memotivasi diri untuk berhenti dari pola hidup yang tidak sehat.

Pada keluarga Ny.SS diberikan intervensi nonmedikamentosa berupa: 1) Edukasi mengenai penyakit Benign Paroxysmal Positional Vertigo (BPPV) kepada pasien dan keluarganya, 2) Edukasi kepada pasien untuk melakukan kontrol rutin tekanan darah dan kembali ke puskesmas jika keluhan BPPV menetap setelah obat habis, 3) Edukasi kepada pasien untuk makan makanan yang bergizi dan seimbang, 4) Edukasi mengenai gaya hidup sehat, cara melatih diri sendiri untuk membentuk gaya hidup sehat, 5) Memberikan edukasi mengenai latihan vestibuler yaitu Epley maneuver untuk mengurangi kekambuhan dari penyakit BPPV yang diderita pasien seperti yang pernah dilakukan pada saat perawatan di puskesmas,6) Edukasi kepada keluarga untuk berperan dalam mengingatkan pasien mengenai gaya hidup sehat, 7) Edukasi dan motivasi mengenai perlunya perhatian dukungan dari semua anggota 
keluarga terhadap perbaikan penyakit pasien.

Pasien masih merasakan pusing berputar sewaktu perubahan posisi setelah dilakukan Epley maneuver saat perawatan di puskesmas, walaupun tidak sehebat yang pertama namun pasien masih takut untuk menggerakkan kepalanya. Terlihat bahwa terapi medikamentosa dan nonmedikamentosa yang diberikan saat perawatan dan setelah pasien pulang dari puskesmas memberikan respon yang memuaskan, sesuai dengan literatur dimana pilihan terapi untuk BPPV selain menggunakan medikamentosa yaitu dengan terapi Epley Maneuver. Pusing yang masih dirasakan oleh pasien disebabkan karena Epley Maneuver tidak dapat dilanjutkan di rumah. Epley maneuver hanya dapat dilakukan di puskesmas dengan bantuan tim medis. Setelah pertemuan pertama di rumah binaan, penulis melakukan uji literatur untuk menemukan manuver lain yang memiliki efektivitas sama dengan Epley maneuver untuk mencegah kekambuhanBenign Paroxysmal Positional Vertigo (BPPV) kanal posterior dan dapat dilakukan sendiri oleh pasien saat di rumah.

Berdasarkan jurnal yang berjudul Comparison of the effectiveness of BrandtDaroff Vestibular training and EpleyCanalith repositioning maneuver in Benign Paroxysmal Positional Vertigo long term result: $A$ randomized prospective clinical trial, didapatkan bahwa Brandt-Daroff maneuver merupakan latihan vestibuler yang memiliki efektivitas sama dengan Epley maneuver dalam mengatasi rekurensi dari $B P P V$ kanal posterior. ${ }^{[2,11]}$ Brandt-Daroff maneuver ini dapat dilakukan pasien secara mandiri saat di rumah untuk mencegah ke kambuhan.

Telah dilakukan edukasi mengenai Brandt-Daroff maneuver (16 Mei 2019) kepada keluarga dan pasien. Dijelaskan bahwa manuver ini dapat meringankan terjadinya rekurensi pada pasien BPPV.
Selain itu, pada kunjungan kedua ini dicarikan alternatif pemecahan masalah masalah yang ada pada keluarga dengan metode family conference serta diberikan edukasi mengenai penyakit lain yang diderita oleh pasien dan keluarga seperti hipertensi dan hiperkolesterolemia dan cara pencegahan agar tidak menjadi suatu komplikasi yang berat.

Didapatkan hasil evaluasi (23 Mei 2019) bahwa keluhan pusing berputar dirasakan pasien berkurang. Brandt-Daroff maneuver masih memprovokasi terjadinya vertigo dan nistagmus posisional, namun dengan intensitas yang telah jauh berkurang. Pasien mampu menyelesaikan satu putaran lengkap Brandt-Daroff maneuver dan mengalami perbaikan dengan terapi yang diberikan. BrandtDaroff maneuver dan Epley maneuver mempunyai prinsip terapi yang sama, yaitu mendorong otokonia untuk kembali ke utrikulus melalui ujung kanal nonampulatory dengan bantuan gravitasi. ${ }^{[2,8]}$ Pasien mengatakan bahwa pasien telah selesai meminum obat yang diberikan dan sesuai dengan yang dijelaskan sebelumnya. Suami dan anak pasien ikut serta dalam mengingatkan pasien untuk minum obat. Pasien khawatir tidak dapat mempertahankan gaya hidupnya yang sudah mengurangi konsumsi makanan berlemak dan bersantan Pasien juga mengatakan telah mengikuti saran yang diberikan dalam rangka merubah gaya hidup dengan mulai membiasakan olahraga rutin 1 minggu sekali dan berencana untuk meningkatkan frekuensinya perlahan. Pasien juga mengatakan seringkali melakukan latihan vestibuler Brandt-Daroff maneuver setiap pagi saat bangun tidur, siang hari dan malam hari sebelum tidur sesuai dengan yang sudah diajarkan sebelumnya. Setelah kunjungan ketiga, pasien diminta untuk tetap rutin melakukan latihan vestibuler untuk mencegah kekambuhan.

Hasil evalusasi lanjutan (30 Mei 2019) dinilai keluhan pusing berputar telah berkurang lebih dari $60 \%$. Keluhan pusing 
hanya terasa pada saat bangun dari tidur. Suami dan anak - anak pasien sering memotivasi diri pasien untuk melakukan latihan vestibuler setiap hari.

Pasien mengatakan bahwa suami pasien sudah pulang ke rumah sebelum maghrib, sehingga memiliki waktu lebih banyak bersama keluarga dana semakin dekat dengan anak - anak pasien. Pasien juga mengatakan bahwa suami dan anaknya banyak mendukung pasien selama pengobatan, mengingatkan minum obat, mengingatkan untuk melakukan latihan vestibuler setiap hari, serta mengajak pasien untuk berolahraga bersama.

\begin{tabular}{|c|}
\hline \\
\hline $\begin{array}{l}\text { Pendekatan dokter } \\
\text { emberikan manfaat besar dalam } \\
\text { encegah kekambuhan penyakit BBPV. } \\
\text { alam laporan kasus ini melalui } \\
\text { ndekatan dokter keluarga yang tidak } \\
\text { nya terfokus pada tatalaksana } \\
\text { edikamentosa, tetapi tatalaksana yang } \\
\text { berikan melibatkan intervensi kepada } \\
\text { luarga dan lingkungan sosial pasien } \\
\text { hingga memberikan pemahaman yang } \\
\text { bih dalam mengenai penyakit yang } \\
\text { derita. Cara holistik dan komprehensif } \\
\text { perti ini dapat membantu proses } \\
\text { ngobatan pasien }\end{array}$ \\
\hline
\end{tabular}

\section{SARAN}

Penyakit BBPV adalah penyakit yang memiliki risiko kekambuhan yang sangat besar. Penulis menyarankan agar pasien melakukan latihan vestibuler teratur dan mengganti gaya hidup menjadi lebih sehat. Keluarga dapat terus mendukung dan mengingatkan pasien untuk mengidentifikasi faktor penyebab dan berusaha menghindarinya.

\section{DAFTAR PUSTAKA}

[1] You P, Instrum R, dan Parnes L. Benign Paroxysmal Positional
Vertigo. Laryngoscope Investig

Otolaryngol. 2018;4(1):116-123

[2] Cetin YS, et al. Comparison of the effectiveness of Brandt-Daroff Vestibular training and Epley Canalith repositioning maneuver in Benign Paroxysmal Positional Vertigo long term result: A randomized prospective clinical trial. Pak J Med Sci. 2018;34(3):558-563.

[3] Perhimpunan Dokter Spesialis Saraf Indonesia. Pedoman Tatalaksana Vertigo. Jakarta: PERDOSSI,2012

[4] Lance S, and Mossman SS. Misleading signs in acute vertigo. Pract Neurol. 2018;18(2):162-165

[5] Lim EC, et al. Developing a Diagnostic Decision Support System for Benign Paroxysmal Positional Vertigo Using a Deep-Learning Model. J Clin Med. 2019;8(5):E633

[6] Tan J, Deng Y, Zhang T, dan Wang M. Clinical Characteristics and Treatment Outcomes for Benign Proxysmal Positional Vertigo Comorbid with Hypertension. Acta Otolaryngol. 2017; 137(5):482-484.

[7] Bhattacharyya N, et al. Clinical Practice Guideline: Benign Paroxysmal Positional Vertigo (Update). Otolaryngol Head Neck Surg. 2017; 156(3_suppl):S1-S47.

[8] Gupta AK, Sharma KG, dan Sharma P. Effect of Epley, Semont Mabeuvers and Brandt-Daroff Exercise on Quality of Life in Patients with Posterior Semicircular Canal Benign Paroxysmal Positional Vertigo (PSCBPPV). Indian $\mathrm{J}$ Otolaryngol Head Neck Surg. 2019; 71(1):99-103.

[9] Sanchez-Vanegas G, Casro-Moreno $\mathrm{C}$, dan Buitrago D. Betahistine in the Treatment of Peripheral Vestibular Vertigo: Results of a Real-Life Study in Primary Care. Ear Nose Throal J. 2019; 145561319849946

[10]Kim MB, Lee HS, dan Ban JH. Vestibular suppressants after canalith repositioning in benign paroxysmal 
positional vertigo. Laryngoscope. 2014;124(10):2400-3.

[11] Strupp, M, et al. Long-term prophylactic treatment of attacks of vertigo in Meniere's disease-comparison of a high with a low dosage of betahistine in an open trial.Acta Otolaryngol. 2008;128(5): 520-4.

[12] Perhimpunan Dokter Spesialis Kardiovaskular Indonesia. Pedoman Tatalaksana Hipertensi Pada Penyakit Kardiovaskular. Jakarta: PERKI,2015

[13] Shrout T, Rudy DW, dan Piascik MT. Hypertension update, JNC8 and beyond. Curr Opin Pharmacol. 2017;33:41-46.

[14]Aldemir NM, et al. Amlodipineinduced gingival hyperplasia in chronic renal failure: a case report 